\title{
In memoriam: Professor Syoiti Tanaka (1926-2016)
}

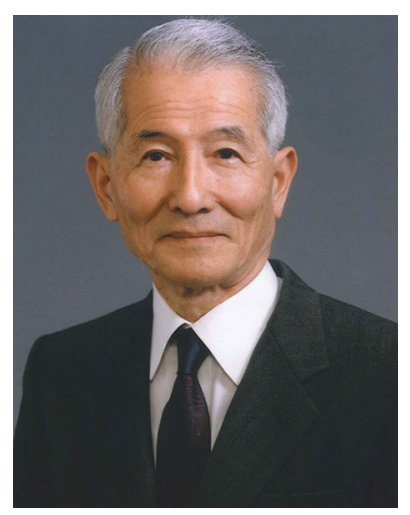

Professor Syoiti Tanaka, an Honorary Member of the Japanese Society of Fisheries Science, Professor Emeritus of the University of Tokyo, and Professor Emeritus of Tokyo University of Fisheries, passed away on January 13, 2016. He was 89-years-old.

Professor Tanaka was born on August 5, 1926 in Taipei, Taiwan. He graduated from the Department of Applied Mathematics, the first Faculty of Engineering of the University of Tokyo, in March 1948. After graduation, he became a researcher at the Central Fisheries Station of Japan. In September 1965, he transferred to the Ocean Research Institute of the University of Tokyo as an Associate Professor from Tokai Regional Fisheries Research Laboratory. In April 1967, he was promoted to the post of professor. He left the university in March 1987, and in April of the same year, became a Professor at Tokyo University of Fisheries, where he served until his retirement from the university in March 1990. He was a member of the Board of Directors of the Institute of Cetacean Research from October 1987 to November 1991. He returned to Tokyo University of Fisheries as the President from November 1991 to November 1995. He rejoined the Institute of Cetacean Research as an Advisor from December 1995 to November 2002.
Professor Tanaka studied stock assessment and fisheries management and conducted mathematical analyses based on theories of population dynamics and statistics. He investigated behaviors of dynamic systems not only analytically but also numerically, although he was never seen to use large computer systems: his research tools were pencil and paper and the computer in his brain, with temporary use of a small calculator. At the age of 75 , he published a review paper entitled "Fisheries management in the 21st century" (Tanaka 2002) in Nippon Suisan Gakkaishi. This paper gives an overview of fisheries management in the twentieth century and discusses desirable management in the twentyfirst century, utilizing key words, feedback management, and Bayesian statistics.

Professor Tanaka also contributed extensively to the Japanese Society of Fisheries Science, serving as Vice President, member of the Board of Directors, and chairperson of various committees. He received the Japanese Society of Fisheries Science Award (Studies on the dynamics and management of fish populations) in 1966 and the Japanese Society of Fisheries Science Award of Merit in the fields of dynamics and management of fish populations in 1988.

Professor Tanaka taught and inspired many young people with his profound knowledge, dignity, and warm personality. We offer our deep condolences to his family and sincerely thank him for his achievements in research and education.

Kunio Shirakihara

Professor, the University of Tokyo 